\title{
Clinical Outcome of Patients Over 90 Years of Age Treated for Chronic Subdural Hematoma
}

\author{
Mauro Dobran, Alessandra Marini, Davide Nasi, Valentina Liverotti, Roberta Benigni, Martina Della Costanza, \\ Fabrizio Mancini, Massimo Scerrati \\ Department of Neurosurgery, Umberto I General Hospital, Università Politecnica delle Marche, Ancona, Italy
}

Objective : Chronic subdural hematoma (CSDH) is one of the most common pathology in daily neurosurgical practice and incidence increases with age. The aim of this study was to evaluate the prognostic factors and surgical outcome of CSDH in patients aging over 90 years compared with a control group of patients aging under 90 years.

Methods : This study reviewed 25 patients with CSDH aged over 90 years of age treated in our department. This group was compared with a younger group of 25 patients aged below their eighties. At admission past medical history was recorded concerning comorbidities (hypertension, dementia, ictus cerebri, diabetes, and heart failure or attack). History of alcohol abuse, anticoagulant and antiplatelet therapy, head trauma and seizures were analyzed. Standard neurological examination and Markwalder score at admission, 48 hours after surgery and 1-6 months follow-up, radiologic data including location and CSDH maximum thickness were also evaluated.

Results : Their mean age was 92.8 years and the median was 92.4 years (range, 90-100 years). In older group, the Markwalder evaluation at one month documented the complete recovery of 24 patients out of 25 without statistical difference with the younger group. This data was confirmed at 6-month follow-up. One patient died from cardiovascular failure 20 days after surgery. The presence of comorbidities, risk factors (antiplatelet therapy, anticoagulant therapy, history of alcohol abuse, and head trauma), preoperative symptoms, mono or bilateral CSDH, maximum thickness of hematoma, surgical time and recurrence were similar and statistically not significant in both groups.

Conclusion : In this study, we demonstrate that surgery for very old patients above 90 years of age affected by CSDH is safe and allows complete recovery. Comparing two groups of patients above and under 90 years old we found that complication rate and recovery were similar in both groups.

Key Words : Hematoma, Subdural, Chronic · Elderly · Neurosurgical treatment · Complications.

\section{INTRODUCTION}

Chronic subdural hematoma (CSDH) is a collection of blood in the subdural space typically found in elderly and rarely in young population. The incidence of $\mathrm{CSDH}$ increases with age : 3.4 per 100000 person-year in people under 60 years

- Received : January 16, 2018 •Revised : March 2, 2018 •Accepted : March 17, 2018

- Address for reprints : Mauro Dobran

Deparment of Neurosurgery, Umberto I General Hospital, Università Politecnica delle Marche, Via Conca, 71, Torrette, Ancona 60020, Italy

Tel : +39-715964567, Fax : +39-715964575, E-mail : dobran@libero.it, ORCID : https://orcid.org/0000-0001-7305-6951

This is an Open Access article distributed under the terms of the Creative Commons Attribution Non-Commercial License (http://creativecommons.org/licenses/by-nc/4.0) which permits unrestricted non-commercial use, distribution, and reproduction in any medium, provided the original work is properly cited. 
of age and 58-80 cases per 100000 person-year in people above 65 years of age $e^{1,3,8,13-15,24)}$. Surgery is the treatment of choice for CSDH, but in patients over their nineties clinical outcome after surgical treatment is not well investigated. This study evaluates risk factors and clinical outcome of CSDH in very elderly patients treated with surgery.

\section{MATERIALS AND METHODS}

This study reviewed 25 patients with CSDH aged over 90 years of age treated in Department of Neurosurgery, Polytechnic University of Ancona, over a period of 5 years, between
2012 and 2016. This group was compared with a control group of 25 patients with an age ranging from 75 to 85 years operated for symptomatic CSDH in the same period.

Surgical indications included symptomatic CSDH with radiological signs of space-occupying intradural lesion with midline shift over $1 \mathrm{~cm}$ (Fig. 1). All asymptomatic patients aging over 90 years-oldaffected by CSDH were treated conservatively. The only contra-indication for surgery in symptomatic patients was the use of anticoagulant therapy or patients with Alzheimer's disease or severe dementia.

$\mathrm{CSDH}$ radiological diagnosis was obtained by computer tomography (CT) scan. At admission past medical history was recorded concerning comorbidities (hypertension, dementia,
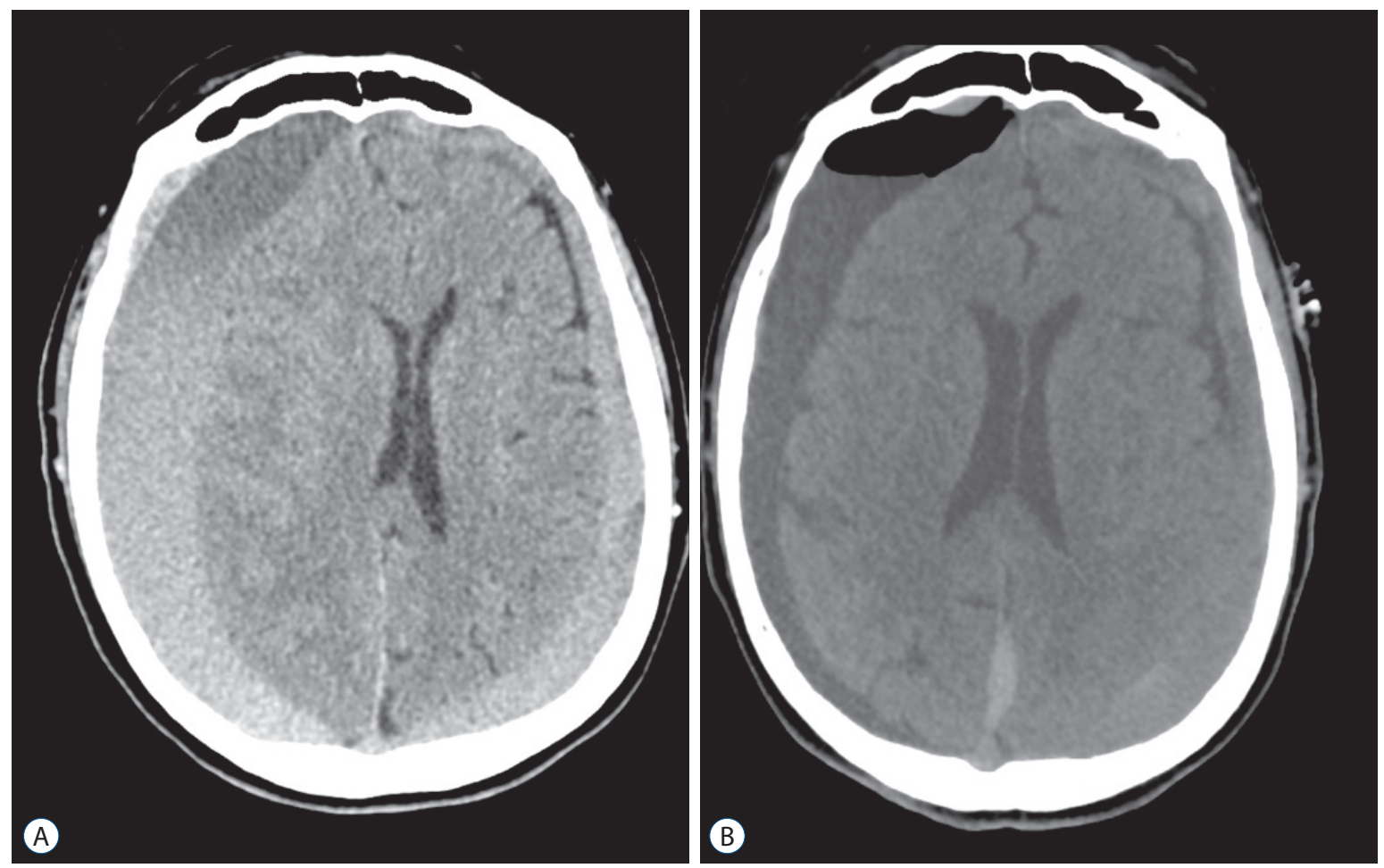

Fig. 1. A and B : Pre-operative and post-operative computer tomography scan images depicting bilateral CSDH in a patient aging over 90 years old. $\mathrm{CSDH}$ : chronic subdural hematoma.

Table 1. The Markwalder grading scale

\begin{tabular}{ll}
\hline Grade & \\
\hline 0 & Neurologically normal \\
1 & Alert and orientated : absence of mild symptoms such as headache, or mild neurological deficit such as reflex asymmetry \\
2 & Drowsy or disorientated, or variable neurological deficit such as hemiparesis \\
3 & Stuporous, but responding appropriately to noxious stimuli, several focal signs such as hemiplegia \\
4 & Comatose with absent motor responses to painful stimuli, decerebrate or decorticate posturing \\
\hline
\end{tabular}


Chronic Subdural Hematoma in Very Elderly Patients | Dobran M, et al.

Table 2. Baseline and post-operative characteristics of two groups (super-aged and young control group)

\begin{tabular}{|c|c|c|c|}
\hline Data analyzed & Group > 90 Y.0. $(n=25)$ & Group <90 Y.O. $(n=25)$ & $p$-value \\
\hline Mean age (years) & 92.4 & 80.4 & $<0.0001$ \\
\hline Sex & & & 0.5 \\
\hline Male & $15(60)$ & $17(68)$ & \\
\hline Female & $10(40)$ & $8(32)$ & \\
\hline Comorbility & & & 0.11 \\
\hline Ictus & $2(8)$ & $2(8)$ & \\
\hline Dementia & $3(12)$ & $1(4)$ & \\
\hline Heart attack & $4(16)$ & $2(8)$ & \\
\hline Atrial fibrillation & $10(40)$ & $4(16)$ & \\
\hline Heart failure & $2(8)$ & $5(20)$ & \\
\hline None & $10(40)$ & $7(28)$ & \\
\hline Pre-operative risk factors & & & 0.33 \\
\hline Antiplatelet therapy & $7(28)$ & $7(28)$ & \\
\hline Anticoagulant therapy & $9(36)$ & $12(48)$ & \\
\hline Hystory of alcohol abuse & $1(4)$ & $2(8)$ & \\
\hline Head trauma & $18(72)$ & $9(36)$ & \\
\hline Pre-operative symptoms & & & 0.2 \\
\hline Headache & $21(84)$ & $20(80)$ & \\
\hline Speech disturbance & $4(16)$ & $10(16)$ & \\
\hline Motor deficit & $16(64)$ & $15(60)$ & \\
\hline Coma & $1(4)$ & $2(8)$ & \\
\hline Seizures & $3(12)$ & $4(16)$ & \\
\hline Location of CSDH & & & 0.5 \\
\hline Left & $5(20)$ & $14(56)$ & \\
\hline Right & $9(36)$ & $6(24)$ & \\
\hline Bilateral & $11(44)$ & $5(20)$ & \\
\hline Maximum thickness of hematoma (cm) & & & 0.5 \\
\hline$<1.5$ & $7(28)$ & $20(80)$ & \\
\hline $1.5-2.2$ & $9(36)$ & $1(4)$ & \\
\hline$>2.2$ & $9(36)$ & $4(16)$ & \\
\hline Surgical time (minnutes) & & & 0.5 \\
\hline$<35$ & $10(40)$ & $9(36)$ & \\
\hline $35-60$ & $10(40)$ & $12(48)$ & \\
\hline$>60$ & $5(20)$ & $4(16)$ & \\
\hline Corticosteroids in post-operative & $6(24)$ & $12(48)$ & 0.5 \\
\hline Post-operative complications & & & 0.033 \\
\hline Recurrence & $5(20)$ & $2(8)$ & \\
\hline Seizure & $1(4)$ & 0 & \\
\hline One-month death & $1(4)$ & 0 & 0.5 \\
\hline
\end{tabular}

Values are presented as number (\%). CSDH : chronic subdural hematoma 
Table 3. The comparison of the Markwalder grading scale between the two groups

\begin{tabular}{|c|c|c|c|c|}
\hline Markwalder grading scale & Group >90 Y.O. $(n=25)$ & Group < 90 Y.O. $(n=25)$ & $p$-value & OR $(95 \% \mathrm{Cl})$ \\
\hline Pre-operative & & & 0.739 & $0.64(0.18-2.28)$ \\
\hline Grade 0 & 0 & 0 & & \\
\hline Grade 1 & $5(20)$ & $7(28)$ & & \\
\hline Grade 2 & $13(52)$ & $12(48)$ & & \\
\hline Grade 3 & $6(24)$ & $3(12)$ & & \\
\hline Grade 4 & $1(4)$ & $2(8)$ & & \\
\hline 48 hours & & & 0.996 & $0.71(0.15-3.24)$ \\
\hline Grade 0 & $12(48)$ & $13(52)$ & & \\
\hline Grade 1 & $9(36)$ & $9(36)$ & & \\
\hline Grade 2 & $3(12)$ & $2(8)$ & & \\
\hline Grade 3 & 0 & $1(4)$ & & \\
\hline Grade 4 & $1(4)$ & 0 & & \\
\hline One-month & & & 0.353 & $0.292(0.04-2.15)$ \\
\hline Grade 0 & $15(62.5)$ & $20(80)$ & & \\
\hline Grade 1 & $6(25)$ & $4(16)$ & & \\
\hline Grade 2 & $3(12.5)$ & $1(4)$ & & \\
\hline Grade 3 & 0 & 0 & & \\
\hline Grade 4 & 0 & 0 & & \\
\hline Six-months & & & 0.353 & $0.292(0.04-2.15)$ \\
\hline Grade 0 & $15(62.5)$ & $20(80)$ & & \\
\hline Grade 1 & $6(25)$ & $4(16)$ & & \\
\hline Grade 2 & $3(12.5)$ & $1(4)$ & & \\
\hline Grade 3 & 0 & 0 & & \\
\hline Grade 4 & 0 & 0 & & \\
\hline
\end{tabular}

Values are presented as number (\%). OR : odds ratio, $\mathrm{Cl}$ : confidence interval

Table 4. The number of case per year in elderly group

\begin{tabular}{|ll}
\hline Number of case per year in elderly group & Value \\
\hline 2016 & $9(36)$ \\
2015 & $7(28)$ \\
2014 & $4(16)$ \\
2013 & $3(12)$ \\
2012 & $2(8)$ \\
\hline
\end{tabular}

Values are presented as number (\%)

ictus cerebri, diabetes, and heart failure or attack). History of alcohol abuse, anticoagulant and antiplatelet therapy, head trauma and seizures were analyzed. Standard neurological examination and Markwalder score ${ }^{18)}$ at admission was used for clinical evaluation, radiologic data including location and
CSDH maximum thickness were also evaluated. Under local anesthesia, a single or double burr hole craniotomy was performed and the hematoma was evacuated by irrigation with physiological saline solution, followed by placement of a subdural closed system drain. The drain was removed 48 hours after surgery and routine CT scan was performed at 48 hours and at 30-day follow-up. Surgical time, use of steroids after surgery and post-operative complications, such as recurrence, were also evaluated.

The outcome was assessed with Markwalder score system 48 hours after surgery and at one and sixth months follow-up. The outcome was dichotomized in favorable outcome (Markwalder grade 0-1) and unfavorable outcome (Markwalder grade 2-4) (Table 1).

For comparing of characteristics of both group we used a 
Table 5. Univariate statistical analysis with chi-square test for pre-operative and post-operative variables affecting the outcome

\begin{tabular}{|c|c|c|c|}
\hline \multirow{2}{*}{ Data analyzed } & \multicolumn{2}{|c|}{ Group >90 Y.O. } & \multirow{2}{*}{$p$-value } \\
\hline & Favorable outcome (Markwalder 0-1) & Unfavorable outcome (Markwalder 2-4) & \\
\hline Location of CSDH & & & 0.902 \\
\hline Monolateral & 11 & 1 & \\
\hline Bilateral & 10 & 2 & \\
\hline Use of antiplatelet or anticoagulant drugs & & & 0.986 \\
\hline Yes & 9 & 2 & \\
\hline No & 12 & 1 & \\
\hline Pre-operative markwalder scale & & & 0.979 \\
\hline $0-1$ & 10 & 1 & \\
\hline $2-4$ & 12 & 2 & \\
\hline History of trauma & & & 0.985 \\
\hline Yes & 13 & 2 & \\
\hline No & 8 & 1 & \\
\hline Surgical time & & & 0.999 \\
\hline$<35-60$ minutes & 15 & 0 & \\
\hline$>60$ minutes & 8 & 3 & \\
\hline Post-operative complications & & & 0.857 \\
\hline Yes & 2 & 3 & \\
\hline No & 19 & 0 & \\
\hline
\end{tabular}

chi-square test for comparison of non-parametric data. Comparison of quantitative parameters was performed using a ttest. Statistical tests were performed using SPSS software (IBM, Chicago, IL, USA).

\section{RESULTS}

Data about 25 super aged patients operated for chronic subdural hematoma were analyzed and described in Table 2. Their mean age was 92.8 years and the median was 92.4 years (range, 90-100). In older group, the Markwalder evaluation at one month documented the complete recovery of 24 patients out of 25 without statistical difference with the younger group. This data was confirmed at 6-month follow-up (Table 3). One patient died from cardiovascular failure 20 days after surgery. In our study the number of elderly patients operated for CSDH increases during recent years (Table 4). The presence of comorbidities, risk factors (antiplatelet therapy, anticoagulant therapy, history of alcohol abuse, and head trauma), pre-operative symptoms, mono or bilateral $\mathrm{CSDH}$, maximum thick- ness of hematoma, surgical time, and recurrence were similar and statistically not significant in both groups, as reported in Table 5 .

\section{DISCUSSION}

Chronic subdural hematoma is one of the most common pathology in daily neurosurgical practice ${ }^{1,8,13,15,16,20,22-25)}$. In this study we evaluated the outcome and risk factors in a series of 25 patients operated for CSDH aged over 90 years of age, compared with a younger control group.

The outcome in our series was overall favorable. Super-aged patients had a good functional recovery assessed with Markwalder score at 6 months : complete in 20 patients (80\%) out of 25 , four patients (16\%) suffered mild symptoms such as gait impairment or minor disturbance of consciousness (Markwalder grade 1) with a good quality of life. One patient died from cardiovascular failure. These data, compared with the outcome of young people, showed no statistical significance. In literature, complete neurological recovery is documented 
in $60-90 \%$ of operated patients ${ }^{1,3,4,14,19,24)}$ but mean age is lower than our study's one.

There have been many reports that antiplatelet and anticoagulant therapies are risk factors for $\mathrm{CSDH}$ and they increase its incidence ${ }^{1,7,15,20,21)}$; in our series $64 \%$ of patients were in treatment with anticoagulant and/or antiplatelet drugs. In patients with CSDH using antithrombotic drugs, careful decision-making is compulsory, because these therapies are more common in non-traumatized CSDH patients with cerebrovascular and/or cardiovascular co-morbidities ${ }^{20)}$. Furthermore, antiplatelet and anticoagulant drugs may increase the probability of CSDH recurrence as well as the VII factor deficit in young patients ${ }^{2,8)}$.

Many studies, reported CSDH recurrence rate around 10$15 \%{ }^{3,8,13,17,25)}$ and elderly patients had higher rate recurrence than younger ones ${ }^{2,5,6,17)}$. In our series the recurrence rate in the elderly group was $20 \%$. According to literature, the higher recurrence value in our series may be due to the small superaged patient sample and age selection; this data did not show statistical significance compared to younger patients.

It is well established that a head trauma, even mild, is the most common cause of CSDH with a incidence rate of 50$80 \%{ }^{3)}$. In the elderly group, history of mild head trauma was documented in $72 \%$ of patients, according to literature ${ }^{2,15)}$. In our series one patient reported a moderate brain trauma with associated vertebral fracture treated with vertebral stabilization $^{9-11)}$. After one month the patient developed CSDH operated with complete recovery.

The most frequent presenting symptoms were consciousness disturbance and hemiparesis; in most cases CSDH diagnosis was delayed because neurological symptoms in superaged patients are frequently related to vascular disease or dementia. In our series the hematoma was bilateral in $44 \%$ of elderly patients; this data is not comparable with rates between 16 and $20 \%$ of other series ${ }^{14)}$ where the mean age was lower than our study's one. The high percentage of bilateral hematoma may be related to the frequent brain atrophy of elderly people $\mathrm{e}^{13,24,26)}$. The hematoma thickness was over $2.2 \mathrm{~cm}$ in $36 \%$ of patients and this may be related to their brain atrophy which let large blood collection in subdural space and delays symptoms recognition ${ }^{24,26)}$.

The complication rate in the perioperative period was low. Careful preoperative evaluation of patient's physical status may be related to this data, meaning that the patient's general condition represents one of the most important factors postoperative outcomes.

The overall mortality rate associated with burr-hole surgery for $\mathrm{CSDH}$ in literature ranges between $0.21 \%$ to $27.5 \%$; in our study of super-aged patients, mortality rate was $4 \%$, in line with literature ${ }^{4,12,14,17,19,24,25)}$. Despite the small sample size of this series, these findings suggest that surgical treatment for $\mathrm{CSDH}$ is safe and effective even for patients ageing over 90 years-old.

\section{CONCLUSION}

In this study, we demonstrate that surgery for very old patients above 90 years of age affected by CSDH is safe and allows complete recovery; this is obtained when the patient's physical status is fair and surgical indications and comorbidities are properly analyzed. Comparing two groups of patients above and under 90 years old we found that complication rate and recovery were similar in both groups.

\section{CONFLICTS OF INTEREST}

No potential conflict of interest relevant to this article was reported.

\section{INFORMED CONSENT}

Informed consent was obtained from all individual participants included in this study.

\section{AUTHOR CONTRIBUTIONS}

\author{
Conceptualization : MD \\ Data curation : AM \\ Formal analysis : DN \\ Methodology : MD \\ Project administration : MS \\ Visualization : FM \\ Writing - original draft : VL, RB \\ Writing - review \& editing : MD, MDC
}




\section{ORCID}

Mauro Dobran https://orcid.org/0000-0001-7305-6951

\section{References}

1. Adhiyaman V, Asghar M, Ganeshram KN, Bhowmick BK : Chronic subdural haematoma in the elderly. Postgrad Med J 78 : 71-75, 2002

2. Ashiyaman $\mathrm{V}$, Chatterjee $\mathrm{I}$ : Increasing incidence of chronic subdural haematoma in elderly. QJM $110:$ 775, 2017

3. Baechli H, Nordmann A, Bucher HC, Gratzl 0 : Demographics and prevalent risk factors of chronic subdural haematoma: results of a large single-center cohort study. Neurosurg Rev 27 : 263-266, 2004

4. Cameron MM : Chronic subdural hematoma: a review of 114 cases. J Neurol Neurosurg Psychiatry Sept $41:$ 834-839, 1978

5. Castro-Rodríguez C, Román-Pena P, Arán-Echabe E, Gelabert-González $\mathrm{M}$ : Chronic subdural haematomas in very elderly patients. Rev Esp Geriatr Gerontol 51 : 309-316, 2016

6. de Araùjo Silva DO, Matis GK, Costa LF, Kitamura MA, de Carvalho Junior EV, de Moura Silva M, et al. : Chronic subdural hematoma and the elderly: surgical result from series of 125 cases: old "horses" are not to be shot! Surg Neurol Int 3 : 150, 2012

7. De Bonis P, Trevisi G, de Waure C, Sferrazza A, Volpe M, Pompucci A, et al. : Antiplatelet/anticoagulant agents and chronic subdural hematoma in the elderly. PLoS One 8 : e68732, 2013

8. Dobran M, lacoangeli M, Scortichini AR, Mancini F, Benigni R, Nasi D, et al. : Spontaneous chronic subdural hematoma in young adult: the role of missing coagulation factor. G Chir $38: 66,2017$

9. Dobran M, lacoangeli M, Di Somma LG, Di Rienzo A, Colasanti R, Nocchi $N$, et al. : Neurological outcome in a series of 58 patients operated for traumatic thoracolumbar spinal cord injuries. Surg Neurol Int 5(Suppl 7) : S329-S332, 2014

10. Dobran M, lacoangeli M, Nasi D, Nocchi N, Di Rienzo A, di Somma L, et al. : Posterior titanium screw fixation without debridement of infected tissue for the treatment of thoracolumbar spontaneous pyogenic spondylodiscitis. Asian Spine J 10 : 465-471, 2016

11. Dobran $M$, Nasi $D$, Brunozzi $D$, di Somma $L$, Gladi $M$, lacoangeli $M$, et al. : Treatment of unstable thoracolumbar junction burst fractures: shortsegment pedicle fixation with inclusion of fracture level versus long-term instrumentation. Acta Neurochir (Wien) 158 : 1883-1889, 2016
12. Gelabert-Gonzáles M, Iglesias-Pais M, García-Allut A, Martínez-Rumbo $R$ : Chronic subdural haematoma: surgical treatment and outcome in 1000 cases. Clin Neurol Neurosurg 107 : 223-229, 2005

13. Jones $\mathrm{S}$, Kafetz $\mathrm{K}$ : A prospective study of chronic subdurale haematomas in elderly patients. Age ageing 28 : 519-521, 1999

14. Karibe H, Kameyama M Kawase M, Hirano T, Kawaguchi T, Tominaga T : Epidemiology of chronic subdural hematomas. No Shinkei Geka 39 : 1149-1153, 2011

15. Kudo H, Kuwamura K, Izawa I, Sawa H, Tamaki N : Chronic subdural hematoma in elderly people: present status on Awaji Island and epidemiological prospect. Neurol Med Chir (Tokyo) 32 : 207-209, 1992

16. Lee KS : Natural history of chronic subdural haematoma. Brain Inj 18 : 351-358, 2004

17. Leroy HA, Aboukaïs R, Reyns N, Bourgeois P, Labreuche J, Duhamel A, et al. : Predictors of functional outcomes and recurrence of chronic subdural hematomas. J Clin Neurosci 22 : 1895-1900, 2015

18. Markwalder TM : Chronic subdural hematomas: a review. J Neurosurg 54 : 637-645, 1981

19. Uno $\mathrm{M}$, Toi $\mathrm{H}$, Hirai $\mathrm{S}$ : Chronic subdural hematoma in elderly patients: is this disease benign? Neurol Med Chir (Tokyo) 57 : 402-409, 2017

20. Mori K, Maeda $\mathrm{M}$ : Surgical treatment of chronic subdural hematoma in 500 consecutive cases: clinical characteristics, surgical outcome, complications, and recurrence rate. Neurol Med Chir (Tokyo) 41 : 371-381, 2001

21. Rust $\mathrm{T}$, Kiemer N, Erasmus $\mathrm{A}$ : Chronic subdural haematomas and anticoagulation or anti-thrombotic therapy. J Clin Neurosci $13: 823-827$, 2006

22. Sambasivan $M:$ An overview of chronic subdural hematoma: experience with 2300 cases. Surg Neurol 47 : 418-422, 1997

23. Spallone A, Giuffrè R, Gagliardi FM, Vagnozzi R : Chronic subdurale haematoma in extremely aged patients. Eur Neurol 29 : 18-22, 1989

24. Tabuchi $\mathrm{S}$, Kadowaki $\mathrm{M}$ : Chronic subdurale hematoma in patients over 90 years old in a super-aged society. J Clin Med Res 6 : 379-383, 2014

25. Toi H, Kinoshita K, Hirai S, Takai H, Hara k, Matsushita N, et al. : Present epidemiology of chronic subdural hematoma in Japan: analysis of 63,358 cases recorded in a national administrative database. J Neurosurg 128 : 222-228, 2018

26. Tsai TH, Lieu AS, Hwang SL, Huang TY, Hwang YF : A comparative study of the patients with bilateral or unilateral chronic subdural hematoma: precipitating factors and postoperative outcomes. J Trauma 68 : 571 575,2010 